\title{
COMMENTARY
}

\section{Protecting rural Canadians from extreme heat}

\author{
Kevin E. Liang MD, Tom Kosatsky MD MPH
}

Cite as: CMAJ 2020 June 15;192:E657-8. doi: 10.1503/cmaj.200004

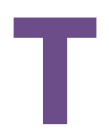

he frequency, intensity and duration of extreme heat events are increasing across Canada. ${ }^{1}$ However, as reflected in recent reports by Environment and Climate Change Canada ${ }^{1}$ and the Council of Canadian Academies, ${ }^{2}$ extreme heat events are regarded as primarily an urban issue. A scan of research and commentaries on the effect of extreme heat on mortality yielded few references to rural Canada (Appendix 1, available at www.cmaj.ca/lookup/suppl/doi:10.1503/cmaj .200004/-/DC1). Furthermore, while several Canadian cities have established emergency response plans for extreme heat, few smaller centres or rural districts have done so (as found in British Columbia $\left.{ }^{3}\right)$. However, it is far from clear that rural residents are less vulnerable to extreme heat events or that cities should be the sole focus of planning for extreme heat events. Here, we consider what makes rural Canadians particularly vulnerable to the effects of extreme heat and discuss how research centred on rural vulnerabilities can inform adaptation strategies for governments, communities and clinicians.

Research in several jurisdictions has shown that mortality increases during hot weather, for both rural and urban settings. A 2017 study of increased mortality associated with hot weather by climatic zone in British Columbia found that the relative impact of elevated temperature was highest in the sparsely populated northern region (population < 215000) compared with the rest of the province, which is more populous and typically warmer. ${ }^{4}$ In the United States, urban (population $>75000$ ) and rural (areas not designated as metropolitan by the US Census Bureau) counties in Ohio had equivalent degrees of mortality above a standard extreme threshold temperature. ${ }^{5} \mathrm{~A}$ comparison of mortality data from Berlin (population density: 3860 residents $/ \mathrm{km}^{2}$ ) and the rural German district of Brandenburg (population density: 86 residents $/ \mathrm{km}^{2}$ ) found similar increases $(>30 \%)$ above baseline in both regions. ${ }^{6}$

That research and public health policy have focused on urban vulnerabilities is perhaps because of the belief that rural residents are protected from heat-capturing "urban heat islands." ${ }^{1,2,7}$ Evidence supports the theory that paved and dark surfaces absorb solar radiation, buildings and factories produce heat, and densely packed urban spaces retain it. ${ }^{1}$ It is also understandable that research on heat-related mortality has focused on the populous regions that have ample temperature, health and socioeconomic data where most Canadians live. However, the notion that cities alone are islands of heat capture and, therefore, more vulnerable to dangerous

\section{KEY POINTS}

- Research in several jurisdictions has shown that mortality increases during hot weather, for both rural and urban settings, but Canada's rural communities face unique vulnerabilities to heat that are often overlooked.

- In Canada, more research on the health effects of and adaptation to extreme heat is required for rural communities.

- Heat-adaptation strategies specific to rural communities are needed in a future in which the frequency, intensity and duration of extreme heat events are expected to increase.

temperature rises is false. Forested urban parks and homes adjacent to them can be cooler than treeless neighbourhoods, and Canadian cities that border oceans or large lakes can be cooler than inland rural regions. ${ }^{8}$ Further, the possible existence of microzones of heat retention must be considered for rural housing built on clay or rock and for homes with limited tree cover.

Beyond exposure itself, vulnerability to extreme heat is also determined by heightened population sensitivity and by limited adaptive capacity, which characterize much of rural Canada. Age is a key determinant of heat-related mortality during extreme heat events. Older adults are more susceptible to extreme heat owing to their lower physiologic capacity to adapt to temperature change. ${ }^{7}$ Data from the 2016 Canadian census show that in rural areas countrywide, more than $19 \%$ of the population is older than 65 years, but this stratum makes up only about $16 \%$ of the nonrural population. ${ }^{9}$

Access to health care and the presence of chronic health conditions, although not completely independent from age, are also key factors affecting vulnerability to extreme heat. High ambient temperatures exacerbate many chronic diseases. ${ }^{\top}$ Across Canada, there are pronounced health inequities between rural and urban communities. A 2012 Canadian Institute for Health Information report found that rural Canadians have a higher burden of chronic conditions, including diabetes, chronic obstructive pulmonary disease and heart disease, than their urban counterparts $(27 \%$ v. $25 \%) .{ }^{10}$ Rural Canadians also report less availability of health care services and increased travel time to reach them. ${ }^{10}$ Although progression to death from extreme heat can be rapid, it is also highly preventable with access to community and medical resources. ${ }^{7}$ 
Finally, differences in income level between rural and urban Canadian communities may play a role in aggravating heat vulnerability. Income alone has been found to be an independent factor for increased morbidity during extreme heat events. ${ }^{11}$ Those with limited financial resources may be more likely to live in older housing where ventilation is inadequate and air conditioning less common. ${ }^{7}$ According to a 2015 report by Strengthening Rural Canada, wages in rural communities are about $30 \%$ lower than they are in urban centres. ${ }^{12}$

Other factors that may further add to rural heat vulnerabilities include occupational exposure, social isolation, building design and lack of public transportation (Appendix 2, available at www.cmaj.ca/lookup/suppl/doi:10.1503/cmaj.200004/-/DC1).

As the most recent Intergovernmental Panel on Climate Change report highlights, some degree of climate change and an associated increase in extreme heat events is inevitable. ${ }^{13}$ In response, many research-derived strategies have been implemented in urban settings. These include changes to the built environment to prevent "urban heat islands," improvements in housing ventilation, and the addition of cooling centres in densely populated areas ${ }^{1,2}$ (Appendix 2).

Particular efforts must be taken to build rural heat resiliency by developing adaptation plans informed by local vulnerabilities. Detailed assessments of rural geography would identify zones subjected to higher heat exposure. Community health surveys would inform the identification of local populations susceptible to extreme heat and the development of services ready to support them during heat events. Rural practitioners need training in identifying patients who are vulnerable to heat and how to mitigate their vulnerabilities. Overlooking rural communities in heat research and response could exacerbate many of the social, economic and health divides that are already widely experienced across Canada.

\section{References}

1. CCCR 2019 Report: Canada's changing climate report. Gatineau (QC): Environment and Climate Change Canada; 2019.

2. Canada's top climate change risks. Ottawa: The Expert Panel on Climate Change Risks and Adaptation Potential, Council of Canadian Academies; 2019.
3. Lubik A, McKee G, Chen T, et al. Municipal heat response planning in British Columbia, Canada. Vancouver: BC Centre for Disease Control; 2017. Available: www. bccdc.ca/resource-gallery/Documents/Guidelines\%20and\%20Forms/Guidelines \%20and\%20Manuals/Health-Environment/BC\%20Municipal\%20Heat\%20Response \%20Planning.pdf (accessed 2019 Dec. 5).

4. Henderson SB, Wan V, Kosatsky T. Differences in heat-related mortality across four ecological regions with diverse urban, rural, and remote populations in British Columbia, Canada. Health Place 2013;23:48-53.

5. Sheridan S, Dolney T. Heat, mortality, and level of urbanization: measuring vulnerability across Ohio, USA. Clim Res 2003;24:255-65. doi: 10.3354/cr024255.

6. Gabriel KM, Endlicher WR. Urban and rural mortality rates during heat waves in Berlin and Brandenburg, Germany. Environ Pollut 2011;159:2044-50.

7. Kovats RS, Hajat S. Heat stress and public health: a critical review. Annu Rev Public Health 2008;29:41-55.

8. Wu X, Zhang L, Zang S. Examining seasonal effect of urban heat island in a coastal city. PLoS One 2019;14:e0217850.

9. Census program. Ottawa: Statistics Canada; modified 2020 Apr. 1. Available: www12.statcan.gc.ca/census-recensement/index-eng.cfm (accessed 2019 Dec. 5).

10. Disparities in primary health care experiences among Canadians with ambulatory care sensitive conditions. Ottawa: Canadian Institute for Health Information; 2012.

11. Fletcher BA, Lin S, Fitzgerald EF, et al. Association of summer temperatures with hospital admissions for renal diseases in New York state: a case-crossover study. Am J Epidemiol 2012;175:907-16.

12. Strengthening rural Canada: fewer and older: population and demographic challenges across rural Canada - a Pan-Canadian report. Vancouver: Strengthening Rural Canada.

13. Global warming of $1.5^{\circ} \mathrm{C}$. Geneva: Intergovernmental Panel on Climate Change; 2019.

\section{Competing interests: None declared.}

This article has been peer reviewed.

Affiliations: Faculty of Medicine (Liang), University of British Columbia; National Collaborating Centre for Environmental Health (Kosatsky), British Columbia Centre for Disease Control, Vancouver, BC

Contributors: Both authors contributed to the conception and design of the work, drafted the manuscript, revised it critically for important intellectual content, gave final approval of the version to be published and agreed to be accountable for all aspects of the work.

Acknowledgements: The authors thank Michele Wiens, Leela Steiner, Tiffany Barker and Sarah Henderson, BC Centre for Disease Control; Sue Pollock, Interior Health Authority; and Dylan Clark, Canadian Institute for Climate Choices.

Correspondence to: Tom Kosatsky, tom.kosatsky@bccdc.ca 